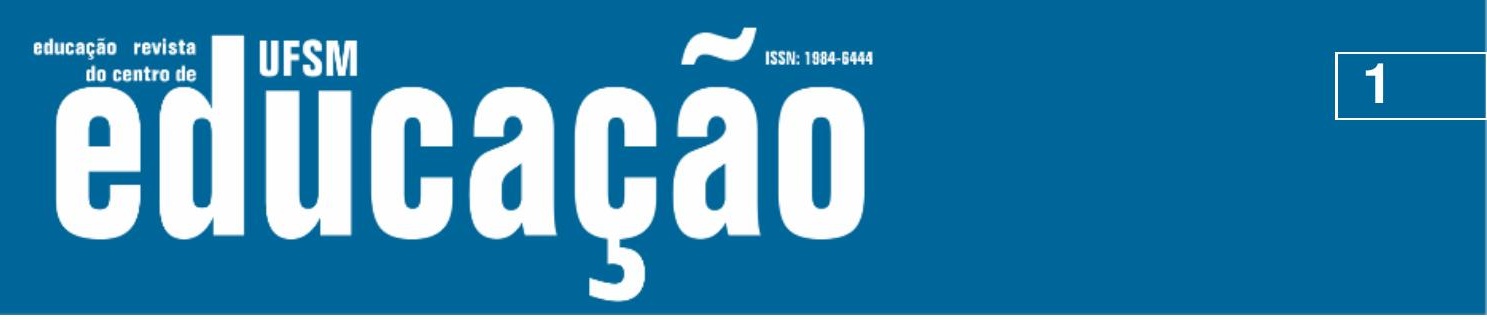

ISSN: 1984-6444 | http://dx.doi.org/10.5902/1984644437288

\title{
Tecnologias e Educação: O discurso da UNESCO'1
}

\author{
Technologies and Education: UNESCO's discourse
}

\author{
* Andréa Villela Mafra da Silva \\ Professora doutora na Fundação de Apoio à Escola Técnica/FAETEC, Rio de Janeiro, Brasil. \\ av.mafra@hotmail.com
}

Recebido em 09 de outubro de 2017

Aprovado em 05 de janeiro de 2018

Publicado em 11 de setembro de 2019

\section{RESUMO}

O artigo apresenta documentos produzidos pela Organização das Nações Unidas para a Educação, a Ciência e a Cultura (UNESCO) que evidenciam a prevalência das Tecnologias de Informação e Comunicação nos encaminhamentos das políticas educacionais contemporâneas contribuindo com o discurso do esvaziamento e da expropriação do trabalho docente. A interpretação do corpus documental neste trabalho está sustentada pela Análise Crítica do Discurso (ACD), formulada por Norman Fairclough (1989; 2001). Fairclough é reconhecido pela sua significativa contribuição ao estabelecer um quadro metodológico que permite investigar a relação entre o discurso e a mudança social, especificamente, com as práticas de produção de linguagem, dentro das quais a vida social é produzida, seja ela econômica, política ou cultural. A teoria de Fairclough se propõe a analisar o papel da linguagem e outros elementos semióticos, tais como imagens, na reprodução das práticas sociais e das ideologias. Conclui-se que os discursos da UNESCO têm em seus princípios a tendência ao fetiche tecnológico sem, no entanto, mencionar as modalidades de ensino ou metodologias necessárias ao uso intensivo das TIC na Educação.

Palavras-chave: Tecnologia; UNESCO; Políticas Educacionais Contemporâneas.

\section{ABSTRACT}

The article presents documents produced by the United Nations Educational, Scientific and Cultural Organization (UNESCO) that highlight the prevalence of Information and Communication Technologies in the direction of contemporary educational policies contributing to the discourse of emptying and expropriation of teaching work. The interpretation of the documentary corpus in this work is supported by the Critical Discourse Analysis (ACD), formulated by Norman Fairclough (1989, 2001). Fairclough is recognized for its significant contribution in establishing a methodological framework that allows us to investigate the relationship between discourse and social change, 


\section{Autuaŗão}

ISSN: 1984-6444 | http://dx.doi.org/10.5902/1984644437288

specifically with the language production practices within which social life is produced, whether economic, political or cultural. Fairclough's theory proposes to analyze the role of language and other semiotic elements, such as images, in the reproduction of social practices and ideologies. It is concluded that the discourses of UNESCO have in their principles the tendency to the technological fetish without, however, mentioning the modalities of teaching or methodologies necessary to the intensive use of ICT in Education.

Keywords: Technology; UNESCO; Contemporary Educational Policies.

\section{Introdução}

$\mathrm{Na}$ agenda das políticas educacionais contemporâneas, a hegemonia neoliberal no campo da Educação se dá através das condicionalidades dos organismos internacionais que reivindicam para si maior representatividade na governança global e ao mesmo tempo defendem a participação do setor privado na esfera educacional pública. Nessa perspectiva, as atuais políticas de formação de professores com base nas ideias de competências e habilidades introduzem a temática da qualidade da educação, claramente referenciando a relação entre educação e produção. Mais especificamente, a apropriação do termo qualidade da educação parece ter origem nas proposições dos Organismos Internacionais (OI). Como se sabe, as proposições dos Organismos Internacionais têm se destacado não só pela insistência, quanto à qualidade da educação empreendida, como também pelo centramento do uso das tecnologias de informação e comunicação na educação.

A produção discursiva presente nos textos e nos manuais produzidos pela Organização das Nações Unidas para a Educação, a Ciência e a Cultura (UNESCO) evidenciam a prevalência das tecnologias nos encaminhamentos das políticas educacionais contemporâneas contribuindo com o esvaziamento e a expropriação do trabalho docente. Observo que o consenso que buscam construir referem-se às tecnologias (TIC) dotadas de grande relevância econômica por constituírem formas de controle político sobre o trabalho docente e, em decorrência, de controle de formação de alunos adequados às necessidades do processo de acumulação do capital. Deduzo que com a introdução das TIC na Educação há em curso uma nova 


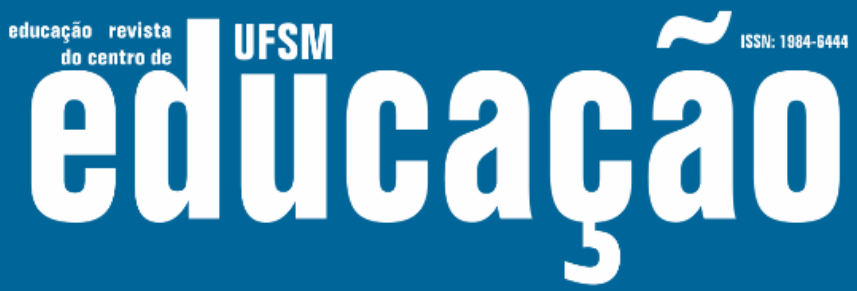

ISSN: 1984-6444 | http://dx.doi.org/10.5902/1984644437288

organização do trabalho e formação docente alinhado ao controle da qualidade total do processo escolar. Em termos de políticas de formação de professores, as repercussões desta formação estão postas nos sistemas educativos e nos contextos que Ihes dão sentido e significado, como na escola. Na prática, é possível constatar um hiato significativo entre a adoção das tecnologias nas escolas e a utilização destes recursos pelos professores. Por um lado, há o estímulo à adoção da tecnologia nos processos pedagógicos e, por outro lado, contraditoriamente, nem sempre há condições de infraestrutura nas escolas que possibilitem o uso das TIC. Leher (2010) trata dessa questão, voltando-se principalmente ao determinismo tecnológico das políticas educacionais, sob influência de Organismos Internacionais, que provoca a expropriação do conhecimento do professor. Um exemplo é a perspectiva das políticas de formação de professores que, de modo geral, associam os conceitos de competência e de qualidade para validar o perfil de profissional que se pretende formar. Os significados destes conceitos - competência e qualidade - variam de acordo com a argumentação presente no discurso quanto ao controle ideológico que se pretende alcançar.

Uma apropriação do conceito de competência é feita por Fairclough (2001) no contexto do discurso educacional comodificado. $\mathrm{O}$ autor comenta que o discurso educacional é dominado por um vocabulário de habilidades, que incluem não só a palavra "habilidade", como também palavras associadas, como "competência". $\mathrm{Na}$ análise faircloughiana, o conceito de habilidades pressupõe duas construções contraditórias. De um lado, o conceito de habilidade "tem implicações ativas e individualistas: habilidades são atributos apreciados pelos indivíduos, estes diferem em tipos e graus de habilidade, e está aberto a cada um aperfeiçoar as habilidades ou acrescentar novas habilidades" (FAIRCLOUGH, 2001, p. 257). e por outro lado, o conceito de habilidade "tem implicações normativas, passivas e objetificadoras: todos os indivíduos adquirem elementos de um repertório social comum de habilidades por meio de procedimentos de treinamento institucionalizados" (FAIRCLOUGH, 2001, p. 257) conferindo pouco espaço à individualidade.

No Brasil, as ações da UNESCO têm priorizado projetos, programas e debates centrados nas relações entre as TIC e Educação, fundamentalmente, nas áreas de 


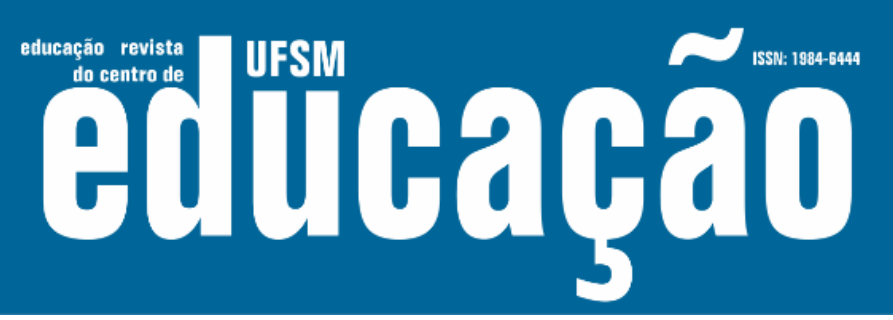

ISSN: 1984-6444 | http://dx.doi.org/10.5902/1984644437288

avaliação de resultados e formação de professores (UNESCO, 2008; 2016a; 2016b). As condicionalidades da UNESCO preconizam o uso intensivo das TIC na Educação para "promover conscientização política, cidadania e garantir aos jovens um lugar no mercado" (UNESCO, 2008, p. 02). O principal pilar que sustenta o discurso da UNESCO é que a Educação deve atender as exigências econômicas e sociais do mundo contemporâneo, através do uso intensivo das TIC.

\title{
O discurso da Organização das Nações Unidas para a Educação, a Ciência e a Cultura (UNESCO)
}

\begin{abstract}
El nuevo entorno em que se desarrolla la educación superior una vez concluído el período de Universidad de masas, ha hecho de la calidad de la docencia el principal elemento diferenciador. En este nuevo contexto, de "Accountability" (rendición de cuentas) el profesorado es la piedra de toque principal de la reforma universitaria. El gran reto es adaptar su papel a la nueva realidad en donde el aprendizaje ya no se concentra exclusivamente en el aula sino que pasa también por el acceso a las Tecnologias de la Comunicación (TIC), por el aula virtual y por la enseñanza semipresencial y a distância. UNESCO. Organização das Nações Unidas para a Educação, Ciência e Cultura. Cátedra UNESCO de Gestión de la Educación Superior de la UPC: Calidad en la docencia y formación del profesorado (UNESCO, 2001, $\mathrm{s} / \mathrm{p})$.
\end{abstract}

Na epígrafe em destaque sobre o boletim da UNESCO de Gestão da Educação Superior pode-se ler que o grande desafio é adaptar o papel do professor a essa nova realidade onde a aprendizagem não é mais concentrada apenas em sala de aula, mas também através do acesso às tecnologias da comunicação (UNESCO, 2001). Do mesmo modo, é importante citar os Parâmetros Curriculares Nacionais que à luz das recomendações da Comissão Internacional sobre Educação para o Século XXI da UNESCO destacam a relevância e os impactos que as TIC acarretam aos sistemas e práticas educacionais, particularmente, no que se refere ao Ensino Médio. Sugerem que "(...) as tecnologias da comunicação e informação e seu estudo devem permear o currículo e suas disciplinas" (BRASIL, 2002a, p. 134).

É razoável supero que estes elementos apontam para a possibilidade de configuração de um colonialismo educacional (FERNANDES, 1975, p. 80) evidenciado no lugar central das TIC nos discursos dos Organismos Internacionais e nos encaminhamentos das políticas educacionais brasileiras contemporâneas. Sob a 


\section{$\sim 7$

ISSN: 1984-6444 | http://dx.doi.org/10.5902/1984644437288

lógica reducionista do determinismo tecnológico é possível observar nos excertos abaixo que apoiados, fundamentalmente, no discurso do esvaziamento e da expropriação do trabalho docente apostam no papel "salvacionista" das TIC:

A UNESCO acredita que as TIC podem contribuir com o acesso universal da educação, a equidade na educação, a qualidade de ensino e aprendizagem, o desenvolvimento profissional de professores, bem como melhorar a gestão, a governança e a administração educacional ao fornecer a mistura certa e organizada de políticas, tecnologias e capacidades (UNESCO, 2016a, p.01, grifos da autora).

O Brasil precisa melhorar a competência dos professores em utilizar as tecnologias de comunicação e informação na educação. A forma como o sistema educacional incorpora as TIC afeta diretamente à diminuição da exclusão digital existente no país. Vários pontos devem ser levados em conta quando se procura responder a questões como: Como as TIC podem ser utilizadas para acelerar o desenvolvimento em direção à meta de "educação para todos e ao longo da vida"? Como elas podem propiciar melhor equilíbrio entre ampla cobertura e excelência na educação? Como elas podem contribuir para reconciliar universalidade e especificidade local do conhecimento? Como pode a educação preparar os indivíduos e a sociedade de forma a que eles dominem as tecnologias que permeiam crescentemente todos os setores da vida e possam tirar proveito delas?

Primeiro, as TICs são apenas uma parte de um contínuo desenvolvimento de tecnologias, a começar pelo giz e os livros, todos podendo apoiar e enriquecer a aprendizagem. Segundo, as TIC, como qualquer ferramenta, devem ser usadas e adaptadas para servir a fins educacionais. Terceiro várias questões éticas e legais, como as vinculadas à propriedade do conhecimento, ao crescente tratamento da educação como uma mercadoria, à globalização da educação face à diversidade cultural, interferem no amplo uso das TIC na educação (UNESCO, 2016a, p. 01).

Apoiada em Fairclough (2001) defendo a ideia de que o discurso deve ser compreendido como uma forma de ação historicamente situada, tendo em vista que as estruturas que organizam a produção discursiva nas sociedades produzem a cada novo enunciado uma ação que pode ter como objetivo a manutenção do status quo ou a transformação social. Recordo que os relatórios de monitoramento global da Educação, publicados anualmente pela UNESCO que dão conta das Metas de Educação Para Todos (EPT), acordadas em Dakar, no ano 2000 pretendem determinar quais estratégias, políticas e programas de educação são efetivamente relacionados com as prioridades econômicas, sociais, ambientais e políticas da agenda de desenvolvimento sustentável no Brasil (UNESCO, 2016a). 


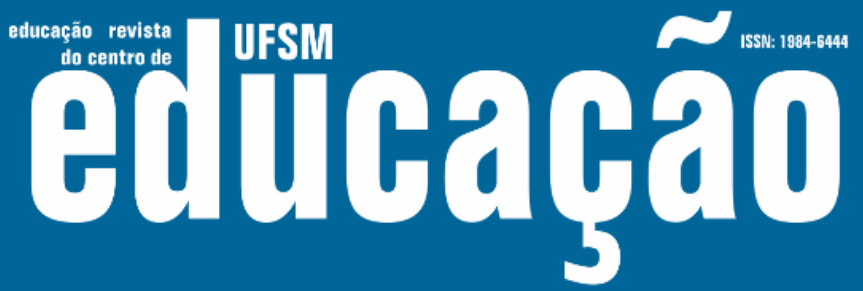

ISSN: 1984-6444 | http://dx.doi.org/10.5902/1984644437288

Como exemplo, o relatório de Monitoramento Global de Educação para Todos 2013/2014 intitulado Ensinar e Aprender: Alcançar qualidade para todos, que salienta a importância do ensino e aprendizagem, "destacando o uso das tecnologias da informação e da comunicação e suas possibilidades de inscrição no processo escolar para o alcance das competências digitais" (UNESCO, 2014, p. 22). Neste relatório a expressão qualidade da educação aparece trinta e oito vezes revelando o entrecruzamento dos discursos do campo educacional e campo econômico. Em termos da interdiscursividade (FAIRCLOUGH, 2001) é possível constatar que a escolha lexical tem como função ideológica a formação de opinião sobre o que é alcançar a qualidade para todos e o que significa educação para todos. Nos excertos abaixo [1] e [2] é possível perceber que os elementos discursivos da UNESCO revelam a noção de que a qualidade do ensino das escolas não é boa e, portanto, predestinadas ao insucesso. Ao mesmo tempo, discursivamente, no excerto [3] a UNESCO vincula às boas práticas de alfabetização ao progresso social e econômico. [1] Cinquenta e sete milhões de crianças estão deixando de aprender, simplesmente por não estarem na escola. O acesso não é o único problema - a baixa qualidade compromete a aprendizagem, mesmo daquelas que frequentam a escola (UNESCO, 2014, p. 03, grifo da autora).

[2] A baixa qualidade da educação significa que milhões de crianças não estão aprendendo sequer o básico. Cerca de 250 milhões de crianças não estão aprendendo as habilidades básicas, embora metade delas tenha frequentado à escola por pelo menos quatro anos (UNESCO, 2014, p. 05, grifo da autora).

[3] A alfabetização universal é fundamental para o progresso social e econômico. Habilidades de letramento são mais bem desenvolvidas na infância, por meio de uma educação de qualidade (UNESCO, 2014, p. 10, grifo da autora).

A destinação deste documento da UNESCO (2014) não apenas prescreve as orientações a serem adotadas, mas também produz "o discurso justificador das reformas que, preparadas em outros contextos", necessitam "erigir consensos locais para sua implementação" (SHIROMA; CAMPOS; GARCIA; 2005, p. 03). 


\title{
DFEM eutuarao

Em publicação posterior, a UNESCO divulga o Relatório Conciso de Monitoramento Global intitulado Educação Para Todos 2000-2015: progressos e desafios (2015), com a seguinte informação:

\begin{abstract}
Este relatório é uma publicação independente, autorizada pela UNESCO em nome da comunidade internacional. E o resultado de um esforço colaborativo, envolvendo membros da equipe do Relatório e muitas outras pessoas, agências, instituições e governos. As designações utilizadas e o material apresentado nesta publicação não implicam a manifestação de qualquer opinião por parte da UNESCO a respeito da condição jurídica de qualquer país, território, cidade, região ou de suas autoridades, tampouco a delimitação de suas fronteiras ou divisas. A seleção e a apresentação dos fatos contidos neste livro, bem como as opiniões nele expressas, são responsabilidade da equipe do Relatório de Monitoramento Global de EPT, e não necessariamente refletem as opiniões UNESCO, nem comprometem a Organização. A responsabilidade geral pelas posições e opiniões expressas no Relatório é de seu diretor (UNESCO, 2015, p. 03).
\end{abstract}

De salientar que, embora o relatório e demais publicações sejam amplamente divulgadas e publicizadas pela UNESCO, o organismo se isenta das responsabilidades pelas posições e opiniões expressas no documento. É através desse recurso de "desresponsabilização" que a UNESCO delega ao autor da publicação a formação de opinião sobre as questões abordadas. Neste caso, a autora da publicação anteriormente destacada é Irina Bokova - Diretora-geral da UNESCO.

A construção discursiva deste relatório baseia-se na intenção de recomendar ações para a agenda global de desenvolvimento sustentável pós-2015. Para tal, o relatório apresenta os objetivos de uma Educação Para Todos enquadrado em noções explícitas da agenda neoliberal, girando em torno de princípios como a mínima intervenção estatal e a privatização. Uma observação mais detalhada da construção discursiva desse relatório traz à tona elementos que operam para legitimar 0 posicionamento ideológico da UNESCO:

Exemplo 1: "Escolas privadas e outras instituições não ligadas ao governo tornaramse importantes provedores de educação" (UNESCO, 2015, p. 21);

Exemplo 2: "Centros de educação não formal oferecem programas de aprendizado flexíveis e acelerados como pontes para o sistema formal ou para crianças pequenas que não tiveram escolarização'" (UNESCO, 2015, p. 21); 


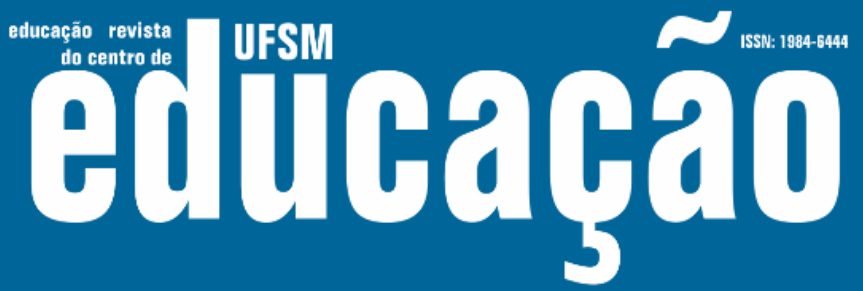

ISSN: 1984-6444 | http://dx.doi.org/10.5902/1984644437288

Exemplo 3: "Escolas comunitárias são frequentemente mais adaptáveis, com melhor relação custo/benefício, maior foco nos alunos e ações mais relevantes às necessidades locais do que as escolas do governo" (UNESCO, 2015, p. 21);

Exemplo 4: "Na falta de planejamento e políticas governamentais adequadas, ONGs e o setor privado desempenharam um papel importante" (UNESCO, 2015, p. 23).

O que está claramente contido no Relatório da UNESCO é a defesa pelo processo de privatização da educação, ao atribuir ao setor privado a tarefa de responder pela formação geral da força de trabalho. Nessa lógica, a meu ver, as formulações da UNESCO são estratégicas aos paradigmas neoliberais que apostam não só na privatização dos serviços públicos como também, na articulação da educação, conhecimento e desenvolvimento como elementos facilitadores à acumulação do capital. Sempre destacando os enunciados educação, conhecimento e desenvolvimento, os dados do relatório são baseados em fatos observados em cerca de duzentos países e territórios, quase anualmente desde 2002 (UNESCO, 2015). Em termos gerais, o relatório pretende fornecer aos formuladores de políticas educacionais indicadores de avaliação para o alcance das metas educacionais após 2015. Especificamente, descrevo a seguir os objetivos das metas descritas no relatório:

Objetivo 1 - "Educação e cuidados na primeira infância: Expandir e melhorar educação e cuidados na primeira infância, principalmente para as crianças mais vulneráveis e em situação desfavorável".

Objetivo 2 - "Educação primária universal: Garantir que, até 2015, todas as crianças, principalmente meninas, crianças em circunstâncias difíceis e as pertencentes a minorias étnicas tenham acesso a uma educação primária completa, gratuita, obrigatória e de boa qualidade".

Objetivo 3 - "Habilidades para jovens e adultos: Garantir que as necessidades de aprendizagem de todos os jovens e adultos sejam alcançadas por meio do acesso equitativo a uma aprendizagem adequada e a programas de habilidades para a vida". Objetivo 4 - "Alfabetização de adultos: Alcançar, até 2015, aumento de $50 \%$ no nível de alfabetização de adultos, principalmente entre mulheres, e o acesso igualitário à educação básica e continuada para todos os adultos". 


\section{Autตaดูão}

ISSN: 1984-6444 | http://dx.doi.org/10.5902/1984644437288

Objetivo 5 - "Paridade e igualdade de gênero: Eliminar as disparidades de gênero na educação primária e secundária até 2005 e alcançar a igualdade de gênero na educação até 2015 , com foco em garantir o acesso completo e equitativo de meninas a uma educação básica de boa qualidade".

Objetivo 6 - "Qualidade da educação: Melhorar todos os aspectos da qualidade da educação e garantir excelência para que resultados de aprendizagem mensuráveis e reconhecidos sejam alcançados por todos, principalmente em alfabetização, conhecimentos básicos em matemática e habilidades essenciais para a vida" (UNESCO, 2015, p. 05-08).

De acordo com o relatório, as estratégias para implementar políticas educacionais "devem ser tecnicamente fortes, politicamente atraentes" (UNESCO, 2015, p. 54); devem ter objetivos claros, capacidades técnicas e estratégicas específicas. No caso do discurso da UNESCO, o léxico tem importância estratégica para a investigação das relações ideológicas (FAIRCLOUGH, 1989). A dimensão ideológica se sustenta no posicionamento favorável à globalização, a agenda neoliberal e nas TIC como "agentes" promotoras da democratização do ensino. Constato essa relação em várias ocorrências:

Estratégia 1: "Investimento significativo na educação básica".

Estratégia 2: "Políticas de EPT dentro de quadros setoriais bem integrados relacionados à eliminação da pobreza".

Estratégia 3: "Engajamento da sociedade civil em estratégias para o desenvolvimento educacional".

Estratégia 4: "Responsabilização na governança e na administração".

Estratégia 5: "Satisfação das necessidades dos sistemas educacionais afetados por conflito e instabilidade".

Estratégia 6: "Estratégias integradas para a equidade de gênero".

Estratégia 7: "Ações para combater o HIV e a AIDS".

Estratégia 8: "Ambientes escolares seguros, saudáveis, inclusivos e homogeneamente equipados".

Estratégia 9: "Profissionalismo, motivação e status dos professores". 


\section{Autตaดูão}

ISSN: 1984-6444 | http://dx.doi.org/10.5902/1984644437288

Estratégia 10: "Aproveitamento das tecnologias de informação e comunicação - O Marco de Dakar enfatizou o potencial das tecnologias de informação e comunicação (TIC) para a Educação Para Todos".

Estratégia 11: "Monitoramento sistemático do progresso".

Estratégia 12: "Base em mecanismos já existentes" (UNESCO, 2015, p. 54, grifos da autora).

A argumentação sobre o uso das TIC faz alusão a promoção, expansão e institucionalização da EaD, a partir de duas demandas. Por um lado, as TIC são enaltecidas, por outro, o professor é concebido como coadjuvante no processo de ensino e aprendizagem. Isto é, a construção discursiva dos excertos, a seguir, se dá a partir do item lexical "potencial", "eficácia" e por outros itens que possuem relação com estes:

Exemplo 1: "Uma aprendizagem aberta e a distância, um modelo potencialmente útil" (UNESCO, 2015, p.23);

Exemplo 2: "As TIC têm o potencial de fomentar o ensino e a aprendizagem [...] A eficácia das TIC também depende de professores treinados" (UNESCO, 2015, p.46); Exemplo 3: "O uso de telefones celulares e outras TIC para a aquisição e a apropriação da alfabetização deveria ser apoiado por meio de parcerias entre o governo e o setor privado" (UNESCO, 2015, p. 52).

A despeito, dos argumentos que anunciam a eficácia das TIC na Educação, sobressai uma multiplicidade de fatores e diversidade de contextos, especificamente relevantes: a incapacidade para aproveitar o potencial que as TIC podem promover ao processo de ensino e aprendizagem, desde a falta ou dificuldade de acesso à internet, até a inadequação de formação dos professores para o uso destas ferramentas. Oportuno lembrar que em maio de 2015, no Fórum Mundial de Educação, em Incheon, na Coréia do Sul, 1.600 participantes, de 160 países, discutiram questões relacionadas à educação inclusiva e equitativa de qualidade ao longo da vida (UNESCO, 2016b).

Deste fórum resultou o Relatório de Monitoramento Global da Educação 2016 Educação para as pessoas e o planeta: Criar futuros sustentáveis para todos (UNESCO, 2016b). Esse documento destaca práticas e políticas sobre como a 


\section{Autuaŗão}

ISSN: 1984-6444 | http://dx.doi.org/10.5902/1984644437288

Educação pode servir de elemento catalisador para a agenda de desenvolvimento sustentável.

A construção discursiva do prefácio do relatório já aponta para o que vai constituir todo o relato: "a educação é o insumo mais importante para todas as dimensões do desenvolvimento sustentável" (UNESCO, 2016b, p.03). O que se vê claramente na constituição discursiva do relatório, em questão, são os efeitos de sentidos que sustentam a relação entre Educação, desenvolvimento social, trabalho e tecnologia. Conforme os excertos abaixo, no bojo do discurso da UNESCO estão as TIC como elo de ligação entre globalização e mundo do trabalho:

Exemplo 1: "Se for para a educação continuar a conduzir o crescimento, ela deverá acompanhar a rápida mudança do mundo do trabalho. A tecnologia não apenas aumentou a demanda por trabalhadores altamente qualificados, mas também diminuiu a demanda por trabalhos de habilidades intermediárias, como vendas, área administrativa e operação de máquinas, tarefas que são mais facilmente automatizadas" (UNESCO, 2016b, p. 16, grifos da autora).

Exemplo 2: "Até 2030, aumentar substancialmente o número de jovens e adultos que tenham habilidades relevantes, inclusive competências técnicas e profissionais, para o emprego, o trabalho decente e o empreendedorismo. [...] Porcentagem de jovens e adultos que alcançaram pelos menos um nível mínimo de proficiência em habilidades de alfabetização digital; [...] Porcentagem de jovens e adultos com habilidades de tecnologias da informação e comunicação (TIC)" (UNESCO, 2016b, p. 36, grifos da autora).

Exemplo 3: "Até 2020, expandir consideravelmente no mundo o número de bolsas de estudo disponíveis para países em desenvolvimento, principalmente para os países de menor desenvolvimento relativo, pequenos Estados insulares em desenvolvimento e países africanos, para inscrição na educação superior, incluindo programas de formação profissional e programas de TIC, engenharia, ciências e áreas técnicas, em países desenvolvidos ou outros países em desenvolvimento" (UNESCO, 2016b, p. 37, grifos da autora).

Exemplo 4: "As TIC tornaram-se essenciais para a vida diária e o trabalho. Na União Europeia, $44 \%$ dos adultos sabiam usar fórmulas aritméticas básicas em planilhas em 


\section{Authabูão}

ISSN: 1984-6444 | http://dx.doi.org/10.5902/1984644437288

2014, com variações de $16 \%$ na Romênia a $63 \%$ na Finlândia. As habilidades de alfabetização digital são um indicador melhor, uma vez que podem ser diretamente avaliadas. Na República Tcheca, $85 \%$ dos alunos do $8^{\circ}$ ano demonstraram conhecimento funcional sobre computadores em 2013 , em comparação com $13 \%$ na Tailândia e 9\% na Turquia" (UNESCO, 2016b, p. 44, grifos da autora).

Como tenho analisado até aqui, o discurso da UNESCO acerca das políticas educacionais, em âmbito mundial, especialmente direcionada aos países mais pobres vem destacando a construção de competências técnicas e profissionais para a inserção no mundo do trabalho. Para a UNESCO (2016b) a maioria dos sistemas educacionais não tem acompanhado a demanda do mercado e "até 2020 , o mundo poderá ter um déficit de 40 milhões de trabalhadores com educação terciária em relação à demanda, e um excesso de 95 milhões de trabalhadores com níveis educacionais mais básicos" (p. 16).

A meu ver, um dos pressupostos básicos do discurso da UNESCO é a ênfase nos elementos dispostos pela Teoria do Capital Humano ao propagar a ideia de que a construção de competências técnicas e profissionais para a inserção no mundo do trabalho, quando certificado pelos sistemas educacionais, poderá contribuir para ampliação da produtividade econômica. Pela própria lógica que permeia a Teoria do Capital Humano, não só a vinculação entre educação e produtividade da economia ganha relevo, como também o papel da educação na diminuição da desigualdade e da pobreza. Existem várias formas de se investir no capital humano e a necessidade de melhorar a educação em todos os níveis tem sido apontada como condição para a inserção na "sociedade do conhecimento". Para a UNESCO, o treinamento dos professores para o uso intensivo das tecnologias em sala de aula é prioridade.

Outro documento que merece análise é intitulado Padrões de Competência em TIC para professores publicado pela UNESCO em 2009. Originalmente, intitulado ICT competency standards for teachers: implementation guidelines a edição na língua portuguesa foi produzida em parceria com a Microsoft Brasil. Esse documento foi elaborado com o intuito de "oferecer um conjunto básico de qualificações, que permita aos professores integrarem as TIC ao ensino e à aprendizagem, para o 


\section{Autuaŗão}

ISSN: 1984-6444 | http://dx.doi.org/10.5902/1984644437288

desenvolvimento do aprendizado do aluno e melhorar outras obrigações profissionais" (UNESCO, 2009).

Sobre as posições ideológicas no uso da linguagem neste documento, não é possível "especificar que itens lexicais num texto se colocam sem considerar as interpretações dos intérpretes desses textos, isto é, entre quais itens os intérpretes realmente discernem as relações" (FAIRCLOUGH, 2001, p. 220). Em nível superficial, essa publicação apresenta diretrizes para o planejamento de programas educacionais direcionados para a formação de habilidades em tecnologia e treinamento de professores para o desempenho de suas atribuições na formação de alunos. Da perspectiva dos professores, a publicação determina que:

Os professores na ativa precisam adquirir a competência que Ihes permitirá proporcionar a seus alunos oportunidades de aprendizagem com apoio da tecnologia. Estar preparado para utilizar a tecnologia e saber como ela pode dar suporte ao aprendizado são habilidades necessárias no repertório de qualquer profissional docente. Os professores precisam estar preparados para ofertar autonomia a seus alunos com as vantagens que a tecnologia pode trazer. As escolas e as salas de aula, tanto presenciais quanto virtuais, devem ter professores equipados com recursos e habilidades em tecnologia que permitam realmente transmitir o conhecimento ao mesmo tempo em que se incorporam conceitos e competências em TIC (UNESCO, 2009, grifos da autora).

Importante comentar que nas formulações da UNESCO o termo habilidade tem sido utilizado como uma espécie de jargão educacional. Como demonstro a seguir, esse termo tem sido utilizado no discurso da UNESCO para descrever as competências necessárias para o desenvolvimento profissional dos professores que utilizarão os recursos de TIC:

Exemplo 1: "Combinando as habilidades das TIC com as visões emergentes na pedagogia, no currículo e na organização escolar, os padrões foram elaborados para o desenvolvimento profissional dos professores que utilizarão as habilidades e os recursos de TIC para aprimorar o ensino, cooperar com os colegas e, talvez, se transformarem em líderes inovadores em suas instituições" (UNESCO, 2009, p. 05, grifo da autora). 


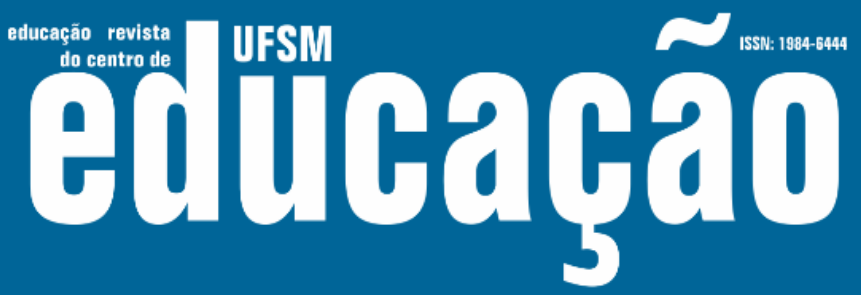

ISSN: 1984-6444 | http://dx.doi.org/10.5902/1984644437288

Exemplo 2: "[...] Expandir o desenvolvimento profissional dos docentes para melhorar suas habilidades em pedagogia, colaboração e liderança no desenvolvimento de escolas inovadoras, usando as TIC; - harmonizar diferentes pontos de vista e nomenclaturas em relação ao uso das TIC na formação dos professores" (UNESCO, 2009, p. 05, grifo da autora).

Exemplo 3: "[...] Aumentar o entendimento tecnológico da força de trabalho incorporando as habilidades tecnológicas ao currículo - ou a abordagem de alfabetização tecnológica; aumentar a habilidade da força de trabalho para utilizar o conhecimento de forma a agregar valor ao resultado econômico, aplicando-o para resolver problemas complexos do mundo real - ou a abordagem de aprofundamento de conhecimento" (UNESCO, 2009, p. 05, grifo da autora).

A meu ver, competências em educação remetem à racionalidade técnica das formas de ensino, bem como na despolitização das práticas educativas, na medida em que a autonomia do professor se apresenta de forma ilusória, pois depende das diretrizes institucionais. Também da perspectiva da competência resulta a supervalorização dos conhecimentos tácitos que, por sua vez, reduzem as exigências de escolaridade, já que decorre antes da experiência, principal requisito para a inserção dos trabalhadores no mundo do trabalho (KUENZER, 2003). O papel que o conhecimento tácito passa a desempenhar a partir da implantação das tecnologias assegura a "banalização das competências, no sentido de sua simplificação, ao permitir que praticamente qualquer pessoa possa aprender a fazer qualquer coisa" (KUENZER, 2003, p. 62) com um simples e rápido treinamento, "não conduz a processos educativos escolares e não escolares mais prolongados, que permitam acesso ao conhecimento teórico articulado às práticas laborais" (KUENZER, 2003, p. $62)$.

Por fim, a interferência do discurso dos organismos internacionais, especificamente da UNESCO, na atual política educacional brasileira, pode ser observada na forma como o trabalho docente tem sido estruturado numa lógica instrumental que prioriza o uso intensivo das TIC (por considerá-las mais eficazes) e secundariza o processo pedagógico que valoriza os conteúdos previstos como necessários à emancipação dos sujeitos. 


\section{Autuaŗão}

ISSN: 1984-6444 | http://dx.doi.org/10.5902/1984644437288

\section{Considerações finais}

Com recorrência as formulações da UNESCO apresentam os mesmos discursos sobre "o potencial das tecnologias de informação e comunicação para a educação para todos" (UNESCO, 2015, s/p); "as TIC têm o potencial de fomentar o ensino e a aprendizagem" (UNESCO, 2015, s/p). De modo geral, é frequente encontrar nos documentos referências ao uso intensivo das TIC na Educação, no entanto sem mencionar as modalidades de ensino ou metodologias necessárias aos objetivos do aprendizado que se deseja alcançar.

Os elementos discursivos da UNESCO me possibilitam a pensar nas relações ideológicas presentes nos documentos, no que se refere a construção textual a partir do léxico tecnologia. A meu ver, nos documentos analisados, as TIC ocupam o lugar de protagonista das ações capazes de melhorar até os resultados da aprendizagem dos estudantes. Suponho que a ideia básica da UNESCO é privilegiar o uso intensivo das TIC, sob a lógica reducionista do determinismo tecnológico que prevê que as ocorrências na Educação podem ser resolvidas com o uso de computadores e conexões com a Internet. Entretanto, como já comentado, há um hiato significativo entre a adoção das tecnologias nas escolas e a utilização destes recursos pelos professores. Por um lado, há o estímulo à adoção da tecnologia nos processos pedagógicos e, por outro lado, contraditoriamente, nem sempre há condições de infraestrutura nas escolas que possibilitem o uso das TIC.

A despeito, dos argumentos da UNESCO (2001, 2008, 2016b) que anunciam a eficácia das TIC na Educação, sobressai uma multiplicidade de fatores e diversidade de contextos, especificamente relevantes: a incapacidade para aproveitar o potencial que as TIC podem promover ao processo de ensino e aprendizagem, desde a falta ou dificuldade de acesso à internet, até a inadequação da integração crítica das TIC nos atos de currículo, que inviabiliza avanços significativos em direção a uma efetiva utilização destas ferramentas como estratégias de ensino e aprendizagem nas escolas brasileiras. Embora eu partilhe de posicionamentos críticos sobre o uso intensivo das TIC na Educação, não desconsidero sua importância. Entretanto, o discurso sustentado na ideia de que o uso competente das TIC pode aprimorar a 


\section{T usm Eutlaghat}

ISSN: 1984-6444 | http://dx.doi.org/10.5902/1984644437288

prática pedagógica, por hipótese, não busca problematizar a forma com que as instituições de ensino, de modo geral, têm formado os futuros professores para utilizarem esses recursos em suas salas de aula.

\section{Referências}

BRASIL. Secretaria de Educação Média e Tecnológica. PCN + Ensino Médio. Orientações Educacionais Complementares aos Parâmetros Curriculares Nacionais. Brasília: MEC, 2002.

FAIRCLOUGH, Norman. Language and power. New York: Longman, 1989.

FAIRCLOUGH, Norman. Discurso e mudança social. Brasília: Editora Universidade de Brasília, 2001.

FERNANDES, Florestan. Sociedade de Classes e Subdesenvolvimento. 3. ed. Rio de Janeiro: Zahar, 1975.

KUENZER, Acácia Zeneida. As relações entre conhecimento tácito e conhecimento científico a partir da base microeletrônica: primeiras aproximações. Educar em revista, Curitiba, v. especial, n. 10, p. 13-33, 2003.

LEHER, Roberto. Educação no governo Lula da Silva: A ruptura que não aconteceu. In: MAGALHÃES et al. Os anos Lula: contribuições para um balanço crítico, 20032010. Rio de Janeiro: Garamond, 2010, p.369-412.

SHIROMA, Eneida Oto; CAMPOS, Roselane Fátima; GARCIA, Rosalba Maria Cardoso. Decifrar textos para compreender a política: subsídios teóricometodológicos para análise de documentos. Perspectiva, Florianópolis, v. 23, n. 2, p. 427-446, jul. /dez. 2005.

UNESCO. Organização das Nações Unidas para a Educação, Ciência e Cultura. Cátedra UNESCO de Gestión de la Educación Superior de la UPC: Calidad en la docencia y formación del profesorado. Boletín de Educación Superior, no 1 , $1 / 06 / 2001$.

UNESCO. Organização das Nações Unidas para a Educação, Ciência e Cultura. A Tecnologia, Informação e Inclusão. TICs na Escola. V.01, no 03, 2008. Disponível em: https://goo.gl/suGp0F. Acesso em: 12 mar. 2019.

UNESCO. Organização das Nações Unidas para a Educação, Ciência e Cultura. Padrões de competência em TIC para professores. UNESCO, 2009. Disponível em: https://goo.gl/6m4D87. Acesso em: 11 mar. 2019. 


\section{$=-$ usm \\ $\sim$

UNESCO. Organização das Nações Unidas para a Educação, Ciência e Cultura. Relatório de Monitoramento Global de EPT 2013/2014: Ensinar e aprender: alcançar a qualidade para todos. Paris: Edições Unesco, 2014. 56 p. Relatório conciso. Disponível em: https://goo.gl/QvxjsG. Acesso em: 13 mar. 2019.

UNESCO. Organização das Nações Unidas para a Educação, Ciência e Cultura. Relatório Conciso de Monitoramento Global - Educação Para Todos 2000-2015: progressos e desafios. UNESCO, 2015. Disponível em: https://goo.gl/M6HUIJ. Acesso em: 13 mar. 2019.

UNESCO. Organização das Nações Unidas para a Educação, Ciência e Cultura. Representação da UNESCO no Brasil. UNESCO, 2016a. Disponível em: https://goo.gl/8LZA27. Acesso em: 03 mar. 2019.

UNESCO. Organização das Nações Unidas para a Educação, Ciência e Cultura. Relatório de Monitoramento Global da Educação. UNESCO, 2016b. Disponível em: https://goo.gl/J1a7LO. Acesso em: 12 mar. 2019.

\section{Correspondência}

Andréa Villela Mafra da Silva - Instituto Superior de Educação do Rio de Janeiro Rua Mariz e Barros, 273. CEP 20270-003, Praça da Bandeira, Rio de Janeiro, Brasil.

\section{(c) (i) (8)}

This work is licensed under a Creative Commons Attribution-NonCommercial 4.0 International (CC BY-NC 4.0)

\section{Notas}

\footnotetext{
${ }^{1}$ Este trabalho é parte da minha pesquisa de doutoramento apresentada ao Programa de Pós-Graduação em Educação, da Universidade do Estado do Rio de Janeiro, em outubro de 2017.
} 